\title{
Industrial Pipe Conveyor Belt Orientation Monitoring System
}

\author{
Prof. S. S. Patil \\ Electronics and \\ Telecommunication Department \\ Sinhgad Institute of Technology, \\ Lonavala \\ Saurabh Harihar \\ Electronics and \\ Telecommunication Department \\ Sinhgad Institute of Technology, \\ Lonavala
}

\author{
Ashish Akhade \\ Electronics and \\ Telecommunication Department \\ Sinhgad Institute of Technology, \\ Lonavala
}

\author{
Ajay Jare \\ Electronics and \\ Telecommunication Department \\ Sinhgad Institute of Technology, \\ Lonavala
}

\begin{abstract}
Pipe conveyors, also referred to as tube conveyors, conveyor belts which are loaded with a material to be conveyed and after being loaded are closed into the conformation of tube by overlapping the belt edges. Belts may twist because of uneven loading, uneven guidance through curves, or otherwise poorly aligned systems.

Undesired rotation of the pipe conveyor belt should be avoided and the problem should be corrected as soon as possible to limit, prevent or minimize damage to the system and loss of material.

Keeping in mind the same, we present the development and characterization of an Industrial Pipe Conveyor Belt Orientation Monitoring System. The proposed system is composed of a microcontroller interfaced with Li-Dar sensors and a Wi-Fi module. The design of the monitoring system is such that it can monitor the orientation of the pipe belt from a considerable distance with ease.
\end{abstract} Flight

Keywords-ATmega328P, Li-Dar sensor, pipe belt, Time of

\section{INTRODUCTION}

Pipe belts are predominately employed where bulk material is conveyed in a relatively confined space through horizontal and vertical curves. Many industries use pipe conveyors for their virtue specially to adapt the various topographical conditions. The pipe conveyors are also used for conveying material or long distances up to 1 Kilometer. It helps to isolate the material from the outside environment. Pipe conveyor belts are prone to running off course or twisting under certain operating conditions [1].

Due to disorientation of the Pipe belt, there may be a loss of material that is to be conveyed. The pipe belt also may get damaged. Many of the major issues discussed in the aboveentitled materials like i) The rollers used to forcibly keep the pipe belt in the right orientation causes damage to the pipe belt [2]. ii) There is a requirement to embed a metal stripe in overlap region throughout the length of the belt [6].

In this paper we introduce an "Industrial Pipe Conveyor Belt Orientation Monitoring System". A prototype system has to be designed, developed, and constructed, which is to be integrated with modules, controllable using specific electronic components and custom computer software. Multiple numbers of sensors are integrated into the system including the Wi-Fi module. The system requires the use of ToF (Time of Flight), with custom algorithms being developed to identify undesired rotation. The entire system will be integrated into a fully automated package.

The system enables industries to easily, remotely monitor the orientation of the pipe conveyor belt. The immediate industry worker gets routinely warned about the orientation of the pipe conveyor belt.

\section{OBJECTIVES}

Some of our objectives behind the implementation of the project are as follows:

- The objective of this work focuses on the detection of misaligned orientation of overlapping region of pipe conveyor belt to reduce the loss.

- Finding the location on the pipe belt, where misalignment has occurred.

- Making Pipe belt orientation monitoring easy, efficient, and accurate in rough terrains and topographical regions.

\section{LITERATURE SURVEY}

The introduction of monitoring systems in the industrial sector brought many positives in filling many of the voids in the system. Many of the papers were published namely Contactless conveyor belt monitoring equipment, Pipe belt orientation monitoring, Intro for the bounce force testing system of conveyor belt, and so on. Many of the major issues discussed in the above-entitled were that, the rollers used to forcibly keep the pipe belt in right orientation causes damage to the pipe belt [2], there is a requirement to embed a metal stripe or rod in overlap region throughout length of belt [6], analysis of bending stiffness and form force [5], use of camera and light beam and an optoelectronic system equipped with a compressed-air clearing device [6]. Use of emitters and detectors separately [3]. In order to monitor the orientation of the pipe conveyor belt remotely, contactless and without modifying the material of original pipe belt, 
without doing any harm to the pipe belt we developed the pipe conveyor belt orientation monitoring system.

\section{HARDWARE SPECIFICATIONS}

\section{A. ATmega328P Microcontroller:}

The microcontroller used here is ATmega3288P it has three ports. The AT mega328P microcontroller is to be interfaced with sensors and a Wi-Fi module for monitoring the orientation of the pipe belt. Sensors will give digital signals to the microcontroller; the microcontroller will continuously analyze those signals and will send alerts through the Wi-Fi module.

\section{B. TF-mini Li-Dar sensor:}

The TF-mini is a ToF (Time of Flight) Li-DAR sensor capable of measuring the distance to an object as close as 30 centimeters and as far as 12 meters. TF-mini Li-Dar sensor module has a transmitter and receiver which transmits and receives light waves. Light wave is transmitted through the transmitter then it strikes on an obstacle and returns back to the receiver part of the sensor. TF-mini Li-Dar sensors work on the principle of distance $=$ speed $\mathrm{x}$ time. ToF (Time of Flight) is the time required for light waves to strike on an obstacle and return back to the receiver section of the sensor.

\section{LM317:}

The LM317 device is an adjustable three-terminal positive-voltage regulator capable of supplying more than $1.5 \mathrm{~A}$. over an output-voltage range of $1.25 \mathrm{~V}$. to $37 \mathrm{~V}$. It requires only two external resistors to set the output voltage. LM317 is used in the power supply block of the system. The LM317 voltage regulator includes current limiting, thermal overload protection, and safe operating area protection. Overload protection remain functional even if the ADJUST terminal is disconnected.

\section{System Block Diagram AND SPECIFICATIONS}

\section{A. Block Diagram:}

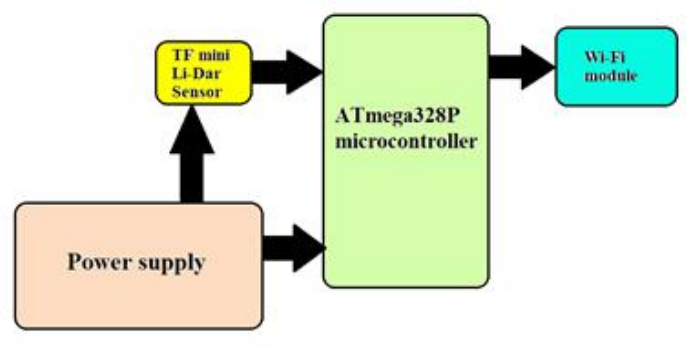

Fig. 1. Block diagram of system

All we need to have is the following components to design a Pipe Belt Orientation Monitoring System apart from a pipe belt and a monitoring device like a smartphone, PC.

\section{1) TF-mini Li-Dar sensor}

TF-mini Li-Dar sensor is fixed at 9 a clock and 3 a clock position of the Pipe belt. Li-Dar follows a simple principle it throws laser light at an object and calculates the time it takes to return to the Li-Dar source. Given the speed at which the light travels (approximately 186,000 miles per second), the process of measuring the exact distance through Li-Dar appears to be incredibly fast. The formula that analysts use to arrive at the precise distance of the object is as follows:
Distance of the object $=($ Speed of Light $\times$ Time of Flight)/2

\section{2) Control Unit}

It consists of a microcontroller. The microcontroller continuously monitors the signals received from sensors when these signals exceed the set threshold value, the microcontroller immediately sends an alert to the monitoring device/ user.

\section{3) Power supply}

The power supply block consists of voltage regulator circuits embedded on a printed circuit board. It provides regulated power to the microcontroller, sensor, and $\mathrm{Wi}-\mathrm{Fi}$ module. Power supply block in our prototype converts $24 \mathrm{~V}$ DC to $5 \mathrm{~V}$ DC.

\section{4) Monitoring System Unit}

Wi-Fi modules will communicate to the Monitoring System Unit in many to one configuration. Wi-Fi module in the Monitoring System Unit will act as a slave and the Wi-Fi module sending TF-mini Li-Dar sensor data will act as master. To send and receive data system will use a MAC address as each module has a unique MAC address. The Monitoring System Unit can identify each sender by its MAC address.

To make this thing easy we will identify each board by a unique id which will map to its MAC address. Monitoring System Unit will use some inbuilt Wi-Fi module libraries and their functions for data reception. Due to the unique id of the sender, it becomes easy to identify the location of the pipe conveyor belt where misalignment has happened.

\section{5) Wi-Fi module}

Wi-Fi module is interfaced to AT-mega 328P and is used to send alerts to the user over the internet. It consumes low power. Wi-Fi module enables remote monitoring. It works on 802.11 IEEE protocol, 2.4 GHz. It uses AT commands to send alerts.

\section{SimULATION ANALYSIS}

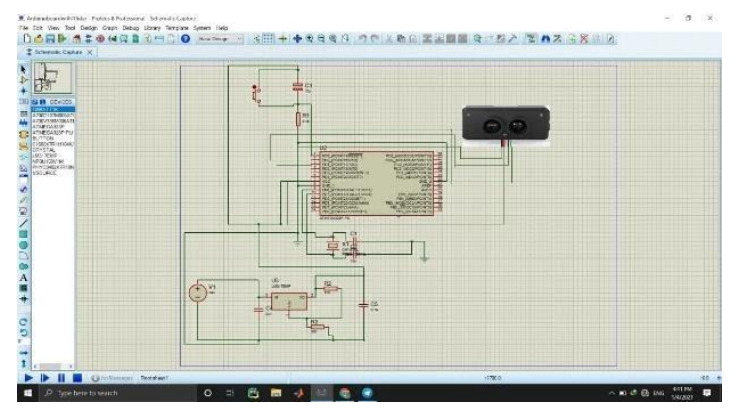

Fig. 2. Simulation diagram

The illustrated simulation shows the interfacing of various components used with the ATmega328P microcontroller which may help in the analysis of the project simulation. Regulator IC provides a power supply to the microcontroller and sensor. The results of the simulation can be analyzed considering the below two cases.

Case-1: Pipe belt is in appropriate orientation: When the overlap region of the pipe belt is at a 12 'o clock position, the sensor detects that the overlap region is at appropriate position. The microcontroller monitors the status of the overlap region and sends a SAFE signal to the monitoring device via a Wi-Fi module. We can observe that the green 
LED glows representing that the pipe belt is working properly. The monitoring device also shows the readings in graphical representation with help of a web server.

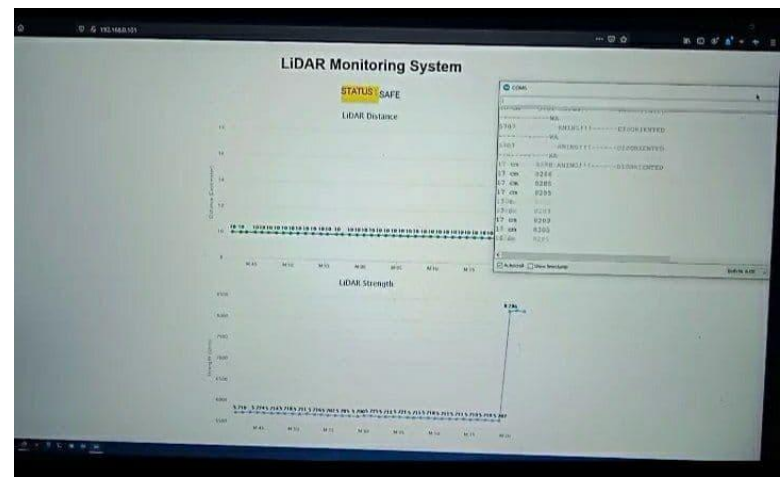

Fig. 3. Case 1 result (Pipe belt is in an appropriate orientation)

Case-2: Pipe belt is working with inappropriate orientation: When the overlap region of the pipe belt comes towards 3 o clock or 9 o clock position, the sensor detects that the overlap region is at inappropriate position. The microcontroller monitors the status of the overlap region and sends an UNSAFE signal to the monitoring device via a Wi$\mathrm{Fi}$ module. We can observe that the red LED glows representing that the pipe belt is not working properly. The monitoring device also shows the readings in graphical representation with help of a web server.

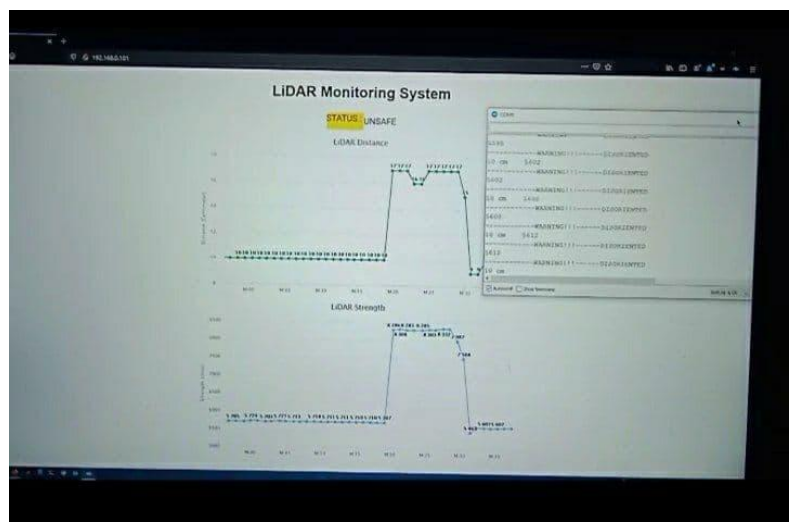

Fig. 4. Case 2 result (Pipe belt is in an inappropriate orientation )

\section{FUTURE SCOPE}

Industrial Pipe Conveyor Belt Orientation Monitoring System can be enhanced in the future.
Rip-detection, temperature detection, material monitoring, can be added to the system.

Following are some applications of the system.

\section{1) Industrial Applications:}

This prototype of the monitoring system can be used in industries where pipe belts are being used.

\section{2) Power Industry:}

This monitoring system can be used in the power industry where a huge amount of material like coal is transported over long distances through a pipe belt.

\section{3) Construction Industry:}

Construction industry where a huge amount of debris is required to be transported through pipe belt.

\section{CONCLUSION}

The pipe belt orientation monitoring is a quite sensitive task. It is better to use an automated monitoring system instead of people monitoring the orientation of the pipe belt manually. We are able to monitor the pipe belt with efficiency and accuracy. The implementation of this prototype greatly helps industries and other sectors where the role of material transportation using pipe belts plays an important role. Wireless monitoring is one of the most important basic needs for all people all over the world.

\section{REFERENCES}

[1] Jack Bruce Wallace, PIPE BELT ORIENTATIONMONITORING, Patent No.: US 9,359,147 B2, United States Patent

[2] Zhou Yi, The intro for the bounce force testing system of conveyor belt; Rubber Science \& Technology Market, Vol. 15, Issue 4, 2008, pp. 28-30.

[3] Rheinische Braunkohlewerke AG, Contactless conveyor belt monitoring equipment - has emitters and detectors signalling alteration in belt position, DE2854562A1 German Patent

[4] Koch Transporttechnik GmbH, Pipe conveyor, DE19716178A1 German Patent

[5] Sun Xiaoxia, Meng Wenjun, Zhao Hui, Yuan Yuan, Yang Zhengmao, Analysis on the Bending Stiffness and the Form Force of the Pipe Conveyor Belt, Sensors \& Transducers, Vol. 161, Issue 12, December 2013, pp. 655-660

[6] Bernd Kisel, DEVICE FOR MONITORING A TUBULAR BELT CONVEYOR SYSTEM, Patent No.: US 6,702,103 B1, United States Patent 